\title{
Voltammetric Determination of Sulfonamides with a Modified Glassy Carbon Electrode Using Carboxyl Multiwalled Carbon Nanotubes
}

\author{
Bao-shan He* and Wen-bo Chen \\ School of Food Science and Technology, Henan University of Technology, \\ 450001 Zhengzhou-PR, China
}

\begin{abstract}
New glassy carbon electrode (GCE) modified with carboxyl multiwalled carbon nanotubes (MWCNTs) and treated with ultrasonic dispersing in $N, N$-dimethylfomamide (DMF) media, namely $\mathrm{DMF} /$ carboxyl/MWCNTs/GCE, was prepared for electrochemical determination of sulfonamides (SAs). Electrochemical behavior of SAs based on DMF/carboxyl/MWCNTs/GCE was investigated by cyclic voltammetry and impedance spectroscopy. The effects of various experimental parameters on the response of electrode such as $\mathrm{pH}$ of buffer, scan rate and the amount of modification were optimized. Under the optimal conditions, the obtained sensor presented linear response to SAs in the range of $5.0 \times 10^{-7}$ to $1.1 \times 10^{-4} \mathrm{~mol} \mathrm{~L}^{-1}$ of sulfonamide $(\mathrm{R}=0.999)$, sulfamethazine $(\mathrm{R}=0.990)$, sulfadiazine $(\mathrm{R}=0.997)$, sulfamethoxazole $(\mathrm{R}=0.996)$ and the limits of detection of $1.65 \times 10^{-8}, 3.19 \times 10^{-8}, 6.76 \times 10^{-8}$ and $9.41 \times 10^{-8} \mathrm{~mol} \mathrm{~L}^{-1}$, respectively. The recoveries were in the range of ca. $85-103 \%$ with relative standard deviation (RSD) $<5 \%$. The sensor was tested by cyclic voltammetry with repeatability and stability of more than $90 \%$ of its original activity. The proposed method might offer feasibility and applicability of the sensor for further complex sulfonamides compounds.
\end{abstract}

Keywords: voltammetric determination, carboxyl, multiwalled carbon nanotubes, sulfamethazine, sulfamethoxazole

\section{Introduction}

Sulfonamides (SAs) have a broad spectrum of antibacterial activity and play an important role as effective chemotherapeutics in bacterial. The structures of SAs consist of benzene ring with amine group $\left(\mathrm{NH}_{2}\right)$ at a $\mathrm{C} 4$ position and sulfonic acid with different alkyl groups (Figure 1). They are widely used in animal husbandry with the purpose to prevent the growth of bacteria, to treat the infections from certain protozoa and microorganisms ${ }^{1,2}$ and to increase their production. ${ }^{3}$ As an additive of preventing bacterial in animal feed, ${ }^{4}$ SAs, however, would bring potential consequences with unauthorized use. ${ }^{3}$ The drug residues in foods, such as milk and meat, may cause allergic reactions, antibiotic resistance and even cancer. Many countries including China have established maximum residue limits (MRLs) for SAs at the total level of $100 \mu \mathrm{g} \mathrm{kg}^{-1}$ in animal meat. ${ }^{5}$ Consequently, it is of grave importance to develop a rapid, sensitive, and accurate method for monitoring the level of $\mathrm{SAs}$ residues in animal meat.

*e-mail: hebaoshan@126.com
Currently, various methods, such as liquid chromatography, ${ }^{6-12}$ capillary electrophoresis, ${ }^{13-16}$ gas chromatography (GC), ${ }^{17-19}$ micellar electrokinetic capillary chromatography, ${ }^{19-22}$ and liquid mass chromatography, ${ }^{23,24}$ have been proposed for analyzing SAs residue in food. These techniques have been proved to be suitable and sensitive for SAs detection. Nonetheless, some of these methods are expensive, time-consuming and tedious, and in some cases the limits of detection is not acceptable. Recently, a research on high-performance liquid chromatography (HPLC), which was coupled with photodiode array detector and mass spectrometry, studied for the determination of SAs residues, shows that the HPLC separation time was still longer than 20 min. ${ }^{25,26}$ Compared with HPLC, electrochemical technique is suitable for on site detection. However, few electroanalytical methods have been used for the determination for SAs residues, most probably due to the problems related to electrode deactivation or fouling. Therefore, choosing the appropriate modification materials is very important.

Carbon nanotubes (CNTs) are novel carbon materials which were firstly found in 1991 by Iijima. ${ }^{27}$ They 


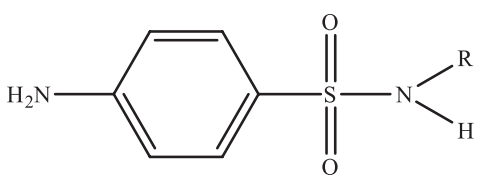

Sulfonamides

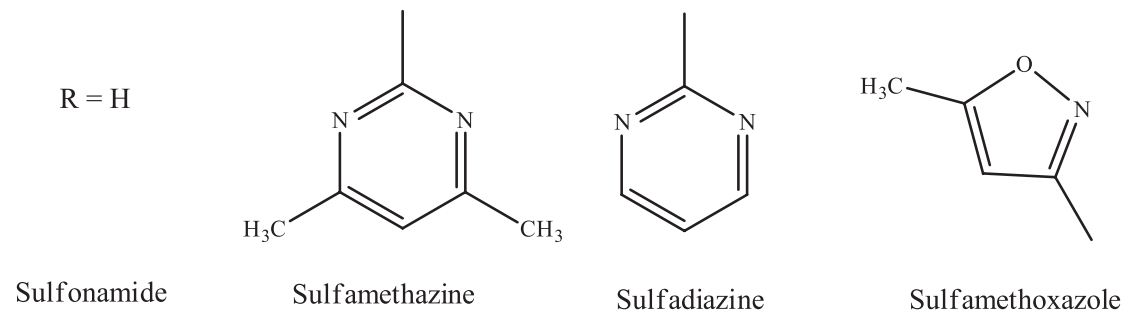

Figure 1. Chemical structure of sulfonamide, sulfamethazine, sulfadiazine and sulfamethoxazole.

have several unique properties such as good electrical conductivity, high chemical stability and extremely high mechanical strength. ${ }^{28}$ Besides, the pentagon and the dimension of bending caused by the defect of multiwalled carbon nanotubes (MWCNTs) shows that they can promote electron-transfer reactions and they have a high electrocatalytic effect when used as modified materials. Therefore, MWCNTs are suitable for the modification of electrodes due to these properties. ${ }^{29}$ Gheibi et al. ${ }^{30}$ used modified MWCNTs paste electrode to determine ascorbic acid with satisfactory results. Sadeghi et al. ${ }^{31}$ developed an electrochemical method for determination of sulfasalazine based on screen printed carbon electrode modified with MWCNTs. However, the untreated MWCNTs modified on the electrode surface could aggregate easily, and make electrode passivated.

The purpose of this paper was to describe the construction and application of a voltammetric sensor for the determination of SAs by using a new glassy carbon electrode (GCE) modified with functional MWCNTs. The MWCNTs were pretreated by using carboxyl method with strong mixed acid and ultrasonic dispersing in $\mathrm{N}, \mathrm{N}$-dimethylfomamide (DMF) media. The resultant DMF/carboxyl/MWCNTs overcame the aggregation on the surface of GCE successfully and performed high electrochemical conductivity and fast electron transfer. The results showed that the DMF/carboxyl/MWCNTs/GCE had good stability, high sensitivity and good repeatability in SAs samples.

\section{Experimental}

\section{Apparatus}

The electrochemical measurements were performed on an electrochemical work station CHI660E (Shanghai
Chenhua Instrument Co., Ltd.). A three-electrode system was adopted, consisting of a modified GCE as working electrode, a platinum wire as counter electrode and a saturated calomel electrode (SCE) as reference electrode. The KQ3200E ultrasonic cleaner was supplied by Kunshan Ultrasonic Instrument Co., Ltd., and UB-7 pH meter was purchased from Sartorius Scientific Instruments Co., Ltd.

\section{Materials and reagents}

DMF and four standard SAs including sulfonamide, sulfamethazine (SM2), sulfadiazine (SDZ), and sulfamethoxazole (SMZ) were analytical grade and purchased from Tianjin Kermel Chemical Reagent Co., Ltd.; multiwalled carbon nanotubes (MWCNTs) were supplied by Beijing Gaoke Technological Material Co., Ltd. Unless stated otherwise, other reagents used were of analytical grade. The pork samples were purchased from local supermarket. The BR buffer solution was blended with $0.04 \mathrm{~mol} \mathrm{~L}^{-1}$ phosphate, $0.004 \mathrm{~mol} \mathrm{~L}^{-1}$ acetic acid, $0.04 \mathrm{~mol} \mathrm{~L}^{-1}$ boric acid and $0.04 \mathrm{~mol} \mathrm{~L}^{-1}$ sodium hydroxide.

\section{Preparation of the working electrode}

Firstly, the unmodified GCE was successively polished to mirror-like with metallographic abrasive paper and 1.00, $0.30,0.05 \mu \mathrm{m}$ graininess $\mathrm{Al}_{2} \mathrm{O}_{3}$ emulsion. ${ }^{32}$ Then, $100 \mathrm{mg}$ of MWCNTs were dispersed with $100 \mathrm{~mL}$ mixed strong acid solution (concentrated $\mathrm{H}_{2} \mathrm{SO}_{4}$ and $\mathrm{HNO}_{3}$ volume ratio of 3:1) and vibrated ultrasonically for $24 \mathrm{~h}$. Afterwards, the carboxyl MWCNTs were put into a vacuum pump for suction, washed until neutral of filtrate and dried at $100{ }^{\circ} \mathrm{C}$ under vacuum environment. The carboxyl process is shown in Figure 2. Then, $5 \mathrm{mg}$ of carboxyl MWCNTs 
were dispersed into $10 \mathrm{~mL}$ DMF in ultrasonic bath for $24 \mathrm{~h}$ to form a homogeneous suspension. After that, $1.5 \mu \mathrm{L}$ of $1.0 \times 10^{-4} \mathrm{~g} \mathrm{~mL}^{-1} \mathrm{DMF} /$ carboxyl/MWCNTs suspension was dropped on a GCE, and dried under the infrared light. Thus, the DMF/carboxyl/MWCNTs/GCE was constructed.

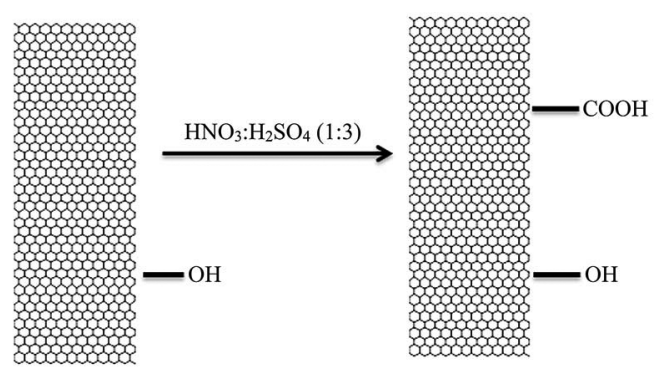

Figure 2. The carboxyl process of multiwalled carbon nanotubes (MWCNTs).

\section{Experimental procedures}

Electrochemical experiments were performed using above three-electrode system. The three electrodes were dipped into BR buffer solution ( $\mathrm{pH}$ 2.0) containing predetermined concentrations of target SA, SM2, SDZ, SMZ under mildly magnetic stirring. Each time before the experiment, the solution must be ventilated for high purity nitrogen ( $\geq 99.999 \%$ ) for $10 \mathrm{~min}$. Amperometric i-t curve measurements were applied to study the detective performance of the electrodes. Cyclic voltammetry (CV) measurements were recorded from 0.6 to $1.5 \mathrm{~V}$ (vs. SCE) with scan rate of $100 \mathrm{mV} \mathrm{s}^{-1}$. All experiments were performed at room temperature.

\section{Results and Discussion}

\section{Morphology of modified electrodes}

Scanning electron microscopy (SEM) was employed to characterize the morphology of GCE modified with MWCNTs and DMF/carboxyl/MWCNTs, respectively. As shown in Figure 3, the MWCNTs film (Figure 3a) polymerized from aqueous solution shows large size and smooth surface (30-90 nm of length). Compared with Figure 2a, the DMF/carboxyl/MWCNTs film (Figure 3b) presents a rather small, compact and homogeneous nano-particle morphology (10-30 nm of length), suggesting the successful formation of carboxyl MWCNTs-DMF composite. Furthermore, the assembly of nanoparticles are beneficial for the diffusion of analytes and would provide highly accessible surface area for the electrocatalytic reaction. These results indicated that the carboxyl method and ultrasonic dispersing in DMF media played an important role in the formation of modified film. As a result, DMF/carboxyl/MWCNTs/GCE showed a significant improvement in electrochemical reactivity and reversibility.
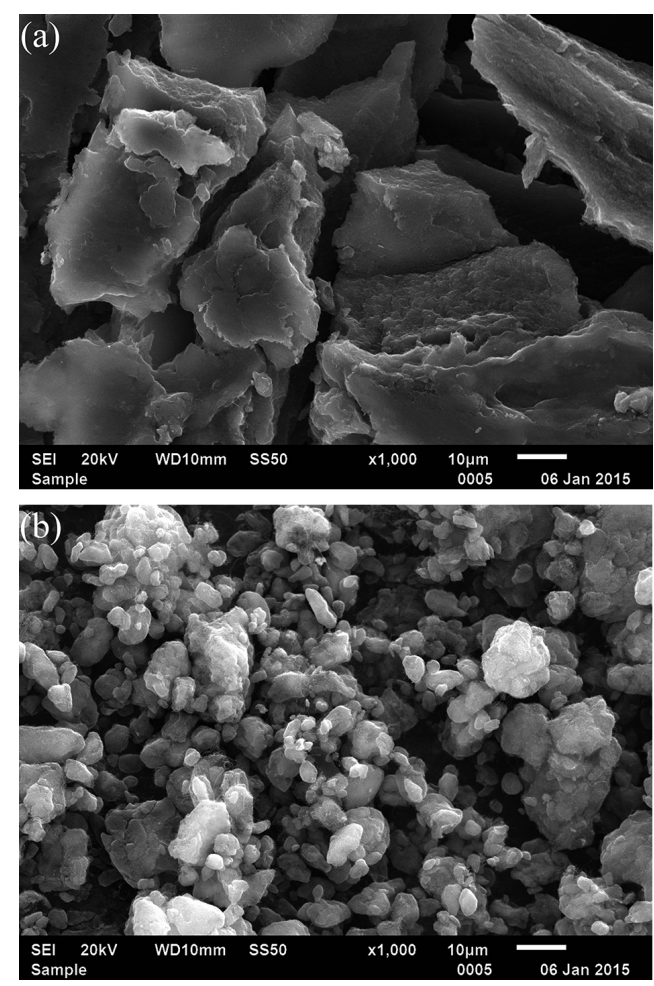

Figure 3. Scanning electron microscopy (SEM) images of (a) multiwalled carbon nanotubes (MWCNTs); and (b) N,N-dimethylfomamide (DMF)/ carboxyl/MWCNTs.

\section{EIS characterization of electrodes}

Electrochemical impedance spectroscopy (EIS) is an effective approach for probing detailed information about interfacial properties of surface-modified electrodes. ${ }^{33}$ The Nyquist plot of EIS commonly includes a semicircular portion at a lower frequencies that corresponded to the electron-transfer limited process and a linear portion at higher frequencies with attributing to the diffusion process. ${ }^{34,35}$ The semicircular diameter of the EIS is equals to the surface electron transfer resistance (Ret). Figure 4 shows EIS at bare GCE (Figure 4, curve $i$ ), $\mathrm{H}_{2} \mathrm{O} / \mathrm{MWCNTs} / \mathrm{GCE}$ (Figure 4, curve ii), DMF/MWCNTs/GCE (Figure 4, curve iii) and DMF/carboxyl/MWCNTs/GCE (Figure 4, curve $i v$ ), respectively. We could obtain a remarkable semicircular portion from curve $i$ (ca. $250 \Omega$ ); after assembling of MWCNTs on the electrode surface, the semicircular diameters (from curve $i i$ to curve $i v$ ) decreased, suggesting that MWCNTs improved conductivity of the electrode and made the electron transfer easier. Ret for DMF/MWCNTs/GCE (Figure 4, curve iii; ca. $50 \Omega$ ) was smaller than that of the $\mathrm{H}_{2} \mathrm{O} / \mathrm{MWCNTs} / \mathrm{GCE}$ 
(Figure 4, curve ii; ca. $120 \Omega$ ), which was because DMF could restrain the agglomeration of MWCNTs effectively. Figure 4, curve $i v$ represents a nearly straight line and the semicircular portion was quite small, which was mainly because the carboxyl MWCNTs dispersing in DMF media increased the reactive site, reduced the interfacial resistance and promoted the electron transfer rate on electrode surface, which was due to their high accessible surface and excellent conductive property. ${ }^{33,36-38}$ Consequently, DMF/carboxyl/ MWCNTs/GCE was selected as the working electrode for further studies.

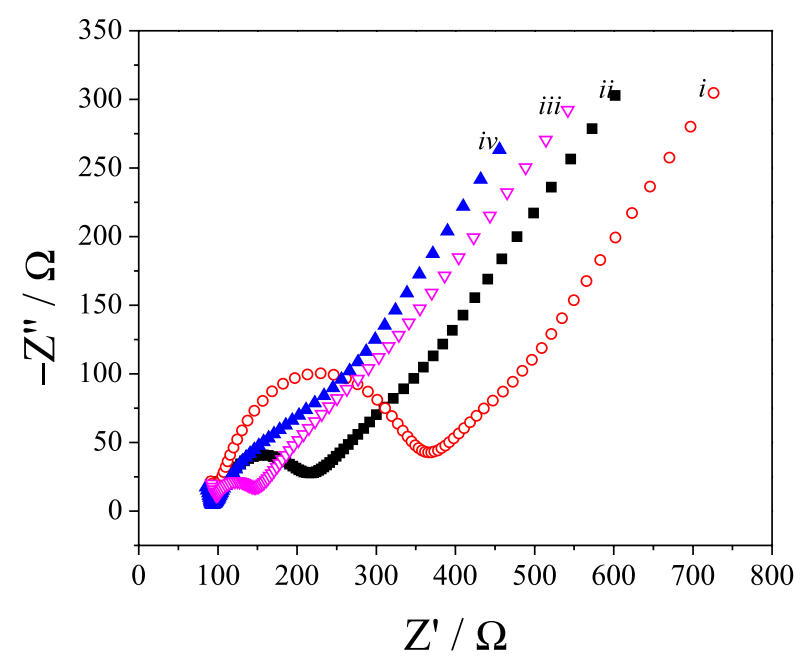

Figure 4. Electrochemical impedance spectroscopy (EIS) recorded at (i) bare glassy carbon electrode (GCE); (ii) $\mathrm{H}_{2} \mathrm{O}$ /multiwalled carbon nanotubes (MWCNTs)/GCE; (iii) DMF/MWCNTs/GC; and (iv) $N, N$ dimethylfomamide (DMF)/carboxyl/MWCNTs/GCE in $10 \mathrm{mmol} \mathrm{L}^{-1}$ $\left[\mathrm{Fe}(\mathrm{CN})_{6}\right]^{3-14-}$ containing $0.1 \mathrm{~mol} \mathrm{~L}^{-1} \mathrm{KCl}$.

\section{Electrochemical behavior of SAs}

In order to test the potential electrocatalytic oxidation of the modified electrodes, cyclic voltammetric responses of bare GCE, $\mathrm{H}_{2} \mathrm{O} / \mathrm{MWCNTs} / \mathrm{GCE}$, DMF/MWCNTs/GCE and DMF/carboxyl/MWCNTs/GCE were obtained in BR buffer solution ( $\mathrm{pH} 2.0$ ) with presence of $1.0 \times 10^{-4} \mathrm{~mol} \mathrm{~L}^{-1}$ of SA and in the potential range of ca. $0.6-1.5 \mathrm{~V}$ with a scan rate of $100 \mathrm{mV} \mathrm{s}^{-1}$. SA could be electrochemically oxidized at $\mathrm{NH}_{2}$ group, but the reduction of $\mathrm{SO}_{2}$ group could occur only at the higher negative potential value. ${ }^{39}$ Therefore, only anodic peaks of SA were test as shown in Figure 5a. It could be seen that there was no obvious anodic peak when the working solution had no SA based on the bare GCE (Figure 5a, curve $i$ ), which was due to the typical electrochemical response of SA corresponding to the oxidation of a phenylamino group..$^{40}$ An oxidation peak current appeared at around $0.988 \mathrm{~V}$ when SA was added in (Figure 5a, curve ii). When the $\mathrm{H}_{2} \mathrm{O} / \mathrm{MWCNTs} / \mathrm{GCE}$ and DMF/MWCNTs/GCE were used as the working electrode, the oxidation peak of SA improved greatly with the anodic potential shifting negatively to about $0.979 \mathrm{~V}$ (Figure 5a, curve iii) and $0.965 \mathrm{~V}$ (Figure 5a, curve $i \mathrm{v}$ ), respectively. Compared to the oxidation peaks of SA obtained on bare GCE, $\mathrm{H}_{2} \mathrm{O} / \mathrm{MWCNTs} / \mathrm{GCE}$ and DMF/MWCNTs/GCE oxidation peaks obtained on DMF/carboxyl/MWCNTs/GCE was further enhanced with the anodic potential shifting negatively to about $0.952 \mathrm{~V}$ (Figure 5a, curve $v$ ). This was because that DMF media could inhibit the agglomeration of MWCNTs effectively, and the reactive area on electrode surface was improved after being modified by the carboxyl MWCNTs, which was useful to promote electron transfer rate. The result was well agreeable to the SEM and EIS analysis.

Cyclic voltammograms of SDZ, SM2 and SMZ were obtained based on DMF/carboxyl/MWCNTs/GCE with the concentration of $1.0 \times 10^{-4} \mathrm{~mol} \mathrm{~L}^{-1}(\mathrm{pH} \mathrm{2.0)}$ ) and in the potential range of ca. $0.6-1.5 \mathrm{~V}$ with a scan rate of $100 \mathrm{mV} \mathrm{s}^{-1}$. As shown in Figure 5b, the anodic potentials of SDZ (Figure 5b, curve viii), SM2 (Figure 5b, curve v), SMZ (Figure 5b, curve vii) were 0.963, 0.927, and $1.013 \mathrm{~V}$, respectively, which proved the good electrochemical respones of DMF/carboxyl/MWCNTs/GCE to SAs.

Influence of scan rates

At pH 2.0 BR buffer solution, the influence of scan rates on the oxidation peak current of $1.0 \times 10^{-4} \mathrm{~mol} \mathrm{~L}^{-1} \mathrm{SA}$ was studied by $\mathrm{CV}$. It could be seen that the oxidation peak current shifted towards positive potentials as the scan rates increased and was linearly increasing with square root of scan rates in the range of 10 to $160 \mathrm{mV} \mathrm{s}^{-1}$, and the linear regression equation was $\mathrm{i}_{\mathrm{pa}}(\mu \mathrm{A})=24.118 \mathrm{v}^{1 / 2}\left[\left(\mathrm{mV} \mathrm{s}^{-1}\right)^{1 / 2}\right]+0.494$ with a correlation coefficient $(\mathrm{R})$ of 0.997 , confirming that the electrochemical reaction of SA was a diffusion-controlled process on the surface of DMF/carboxyl/MWCNTs/GCE, which were in accordance with those of SDZ, SM2 and SMZ.

Influence of $\mathrm{pH}$

Take SA as example, the influence of $\mathrm{pH}$ of the reaction solution containing $1.0 \times 10^{-4} \mathrm{~mol} \mathrm{~L}^{-1} \mathrm{SA}$ was studied in the range of 1.0 to 5.0. As as can be seen in Figure 7b, on the DMF/carboxyl/MWCNTs/GCE, the oxidation peak current of SA increased with the increase of $\mathrm{pH}$ values from 1.0 to 2.0 , and the maximum sensing response was achieved as its value was 2.0. Afterwards, oxidation peak current declined gradually within $\mathrm{pH}$ range of 2.0 to 5.0. The results might be explained that in strong acidic environment, $\mathrm{SA}$ and $\mathrm{H}^{+}$ of the solution combined and formed ammonium salt, and 

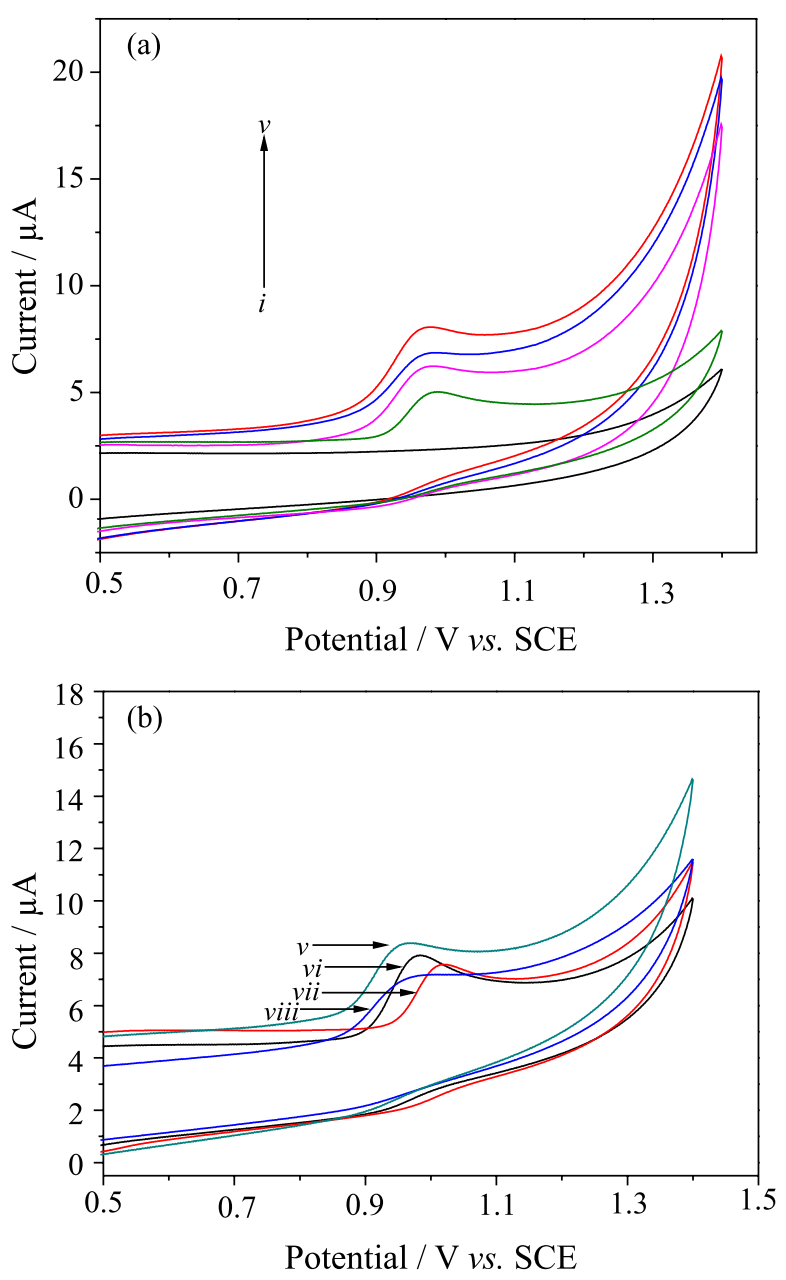

Figure 5. (a) Cyclic voltammograms of Britton-Robinson (BR) buffer solution at bare glassy carbon electrode (GCE; curve $i$ ), $1.0 \times 10^{-4} \mathrm{~mol} \mathrm{~L}^{-1}$ sulfonamide (SA) at bare GCE (curve ii), $\mathrm{H}_{2} \mathrm{O} /$ multiwalled carbon nanotubes (MWCNTs)/GCE (curve iii), $N, N$-dimethylfomamide (DMF)/MWCNTs/GCE (curve iv) and DMF/carboxyl/MWCNTs/GCE (curve $v$ ); and (b) cyclic voltammograms of BR buffer solution at $1.0 \times 10^{-4} \mathrm{~mol} \mathrm{~L}^{-1}$ sulfadiazine (SDZ, curve viii), sulfamethazine (SM2, curve v), SA(curve vi) and sulfamethoxazole (SMZ, curve vii) in DMF/carboxyl/MWCNTs/GCE. Condition: BR buffer solution at $\mathrm{pH} 2.0$, with a scan rate of $100 \mathrm{mV} \mathrm{s}^{-1}$. SCE: Saturated calomel electrode.

reduced the activity of SA. At $\mathrm{pH} 2.0$, SA had admirable oxidative activity and the carboxyl groups of MWCNTs could interact with sulfonamide molecule through the hydrogen bonding. However, in relative weak acidic environment, the carboxyl groups became into anions, which inhibited the hydrogen bonding and leaded to the declined oxidation current peak. It further validated that $\mathrm{H}^{+}$was involved in the electrochemical reaction process. ${ }^{36}$ The influences of $\mathrm{pH}$ of the reaction solution containing $1.0 \times 10^{-4} \mathrm{~mol} \mathrm{~L}^{-1} \mathrm{SDZ}$, SM2 and SMZ were texted based on the same experimental method; the maximum oxidation peaks were achieved when $\mathrm{pH}$ was 2.0 , which consists with the result of SA. Therefore, $\mathrm{pH} 2.0$ was selected for all the subsequent experiments.
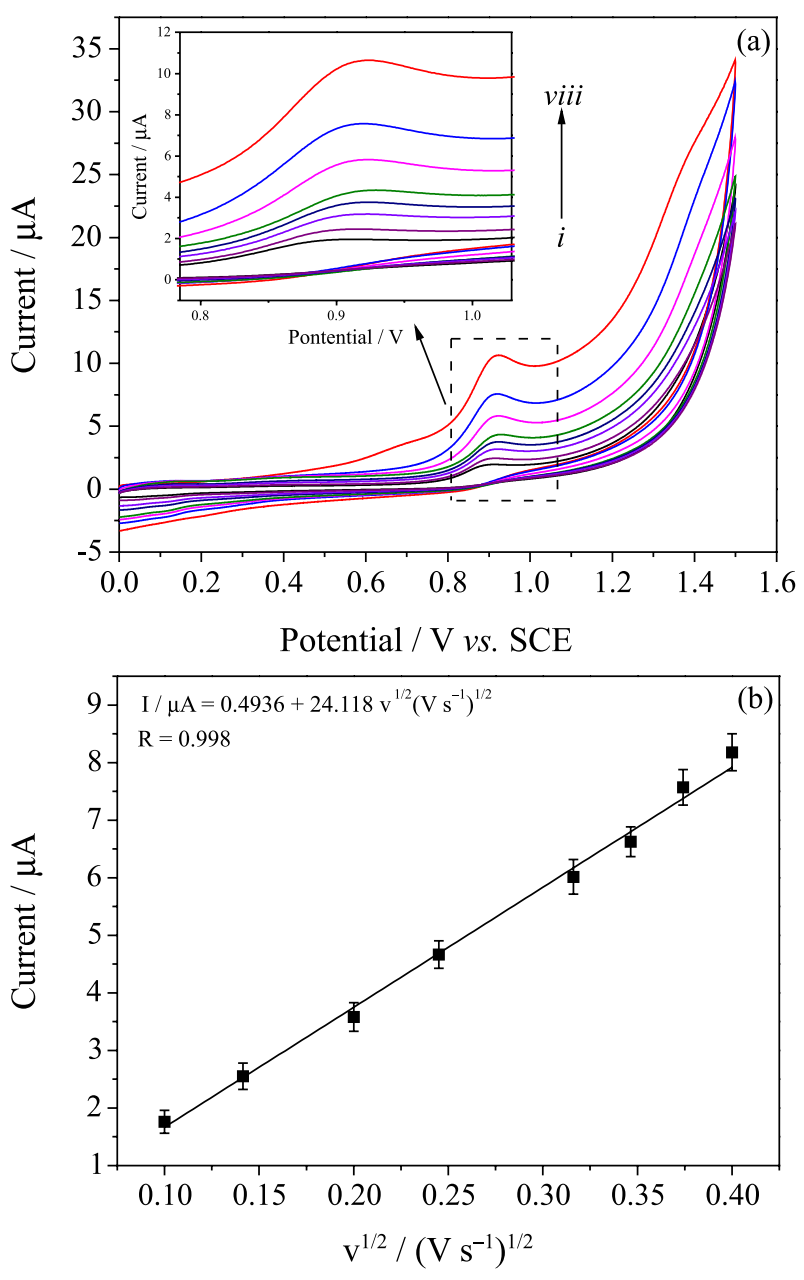

Figure 6. (a) Cyclic voltammograms of $1.0 \times 10^{-4} \mathrm{~mol} \mathrm{~L}^{-1}$ sulfonamide (SA) on $N, N$-dimethylfomamide (DMF)/carboxyl/multiwalled carbon nanotubes (MWCNTs)/glassy carbon electrode (GCE) at pH 2.0 BrittonRobinson (BR) buffer solution and different scan rates: $\mathrm{v}=($ i) 10 , (ii) 20, (iii) 40, (iv) 60, (v) 100, (vi) 120, (vii) 140, and (viii) $160 \mathrm{mV} \mathrm{s}^{-1}$; and (b) linear dependence of peak currents vs. the square root of scan rates. SCE: Saturated calomel electrode.

\section{Optimization of the concentration of carboxyl MWCNTs}

Appropriate concentration of the modified material played an important role on improving the limit of detection; the effect of concentration of carboxyl MWCNTs on oxidation peak current of $1.0 \times 10^{-4} \mathrm{~mol} \mathrm{~L}^{-1}$ $\mathrm{SA}$ was investigated. Figure 8 shows the cyclic voltammograms obtained on GCE modified by using $1.5 \mu \mathrm{L}$ of different concentration of carboxyl MWCNTs in DMF media. As could be seen, the oxidation peak current increased with the concentrations of modified materials from $1.0 \times 10^{-6}$ to $1.0 \times 10^{-4} \mathrm{~g} \mathrm{~mL}^{-1}$ and declined as the concentration exceeded $1.0 \times 10^{-4} \mathrm{~g} \mathrm{~mL}^{-1}$. The oxidation peak current increased due to the incremental reaction area, which improved the electrode activity and the electron transfer rate. Excessive concentration intensified 

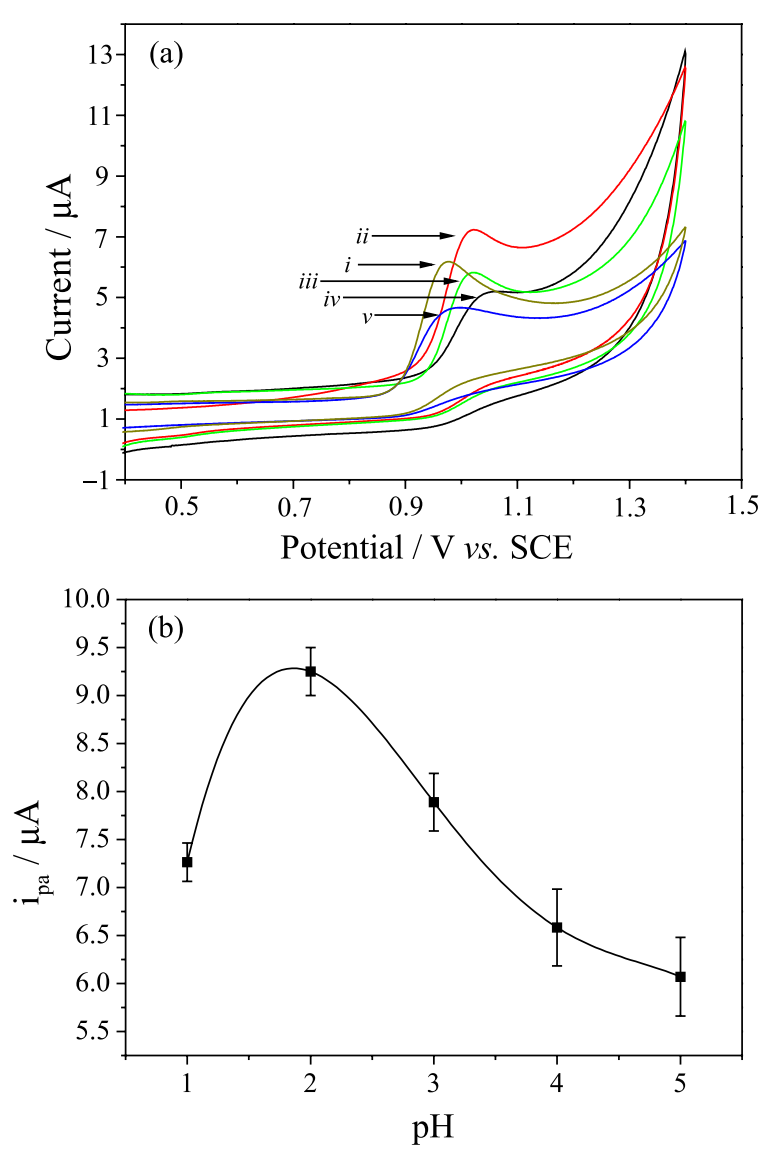

Figure 7. (a) The curves of $i-v$ correspond to the $\mathrm{pH}$ values of 1.0, 2.0, 3.0, 4.0, 5.0; (b) effects of the solution $\mathrm{pH}$ on the oxidation peak current of $1.0 \times 10^{-4} \mathrm{~mol} \mathrm{~L}^{-1} \mathrm{SA}$. SCE: Saturated calomel electrode.

MWCNTs polymerized and made modified electrode unresponsive, and leaded to the oxidation peak current declined. The effect of carboxyl MWCNTs concentration on oxidation peak currents of $1.0 \times 10^{-4} \mathrm{~mol} \mathrm{~L}^{-1} \mathrm{SDZ}$, SM2 and SMZ were also investigated, and the highest activity of DMF/carboxyl/MWCNTs/GCE was obtained when the concentration of carboxyl MWCNTs in DMF media was $1.0 \times 10^{-4} \mathrm{~g} \mathrm{~mL}^{-1}$, which were in accordance with that of SA.

\section{Interference of coexisted substances}

The influence of various substances, which were taken as the potential interfering substances, was investigated under the optimum conditions with $1.0 \times 10^{-4} \mathrm{~mol} \mathrm{~L}^{-1}$ SAs. The tolerance limit was considered as the interferent concentration that caused an approximately $5 \%$ relative error in the current signal for reduction of SAs. ${ }^{41-43}$ If the coexisting interferents made the detection current signal deviation below $5 \%$ under the sufferable coexisting amount, the tested substances were believed that they almost have no interference for the experiment. The results (Tables 1-4)

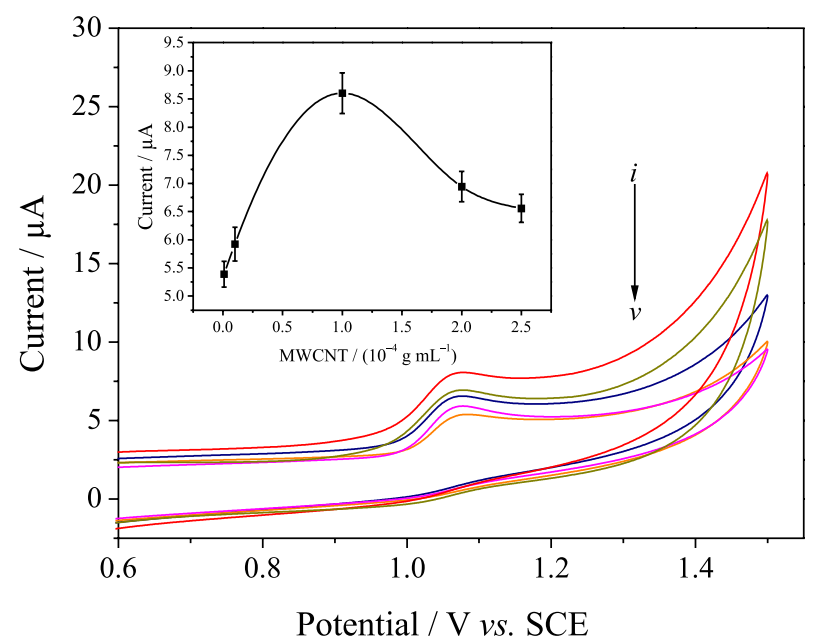

Figure 8. Cyclic voltammograms for $1.0 \times 10^{-4} \mathrm{~mol} \mathrm{~L}^{-1}$ sulfonamide (SA) on glassy carbon electrode (GCE) modified with different concentrations of carboxyl multiwalled carbon nanotubes (MWCNTs) in $N, N$-dimethylfomamide (DMF) media (concentration from $i$ to $v: 1.0 \times 10^{-4}$, $\left.2.0 \times 10^{-4}, 2.5 \times 10^{-4}, 1.0 \times 10^{-5}, 1.0 \times 10^{-6} \mathrm{~g} \mathrm{~mL}^{-1}\right)$. Insert: diagram for peak current and concentrations of carboxyl MWCNTs in DMF media.

showed that 200-fold of glucose, sucrose, ascorbic acid; and 300 -fold of $\mathrm{KCl}, \mathrm{NaCl}, \mathrm{CaCl}_{2}, \mathrm{NH}_{4} \mathrm{Cl}$ and $\mathrm{MgSO}_{4}$ did not significantly affect the oxidation peak currents of SAs. The change rates and relative errors of oxidation peak currents of SA, SDZ, SMZ and SM2 were in the range of ca. $0.43-5.26 \%$ and ca. $0.48-5.00 \%$, suggesting that the coexistence of interferents did not apparently affect the developed sensor and the proposed method might be suitable for the detection of real samples.

Table 1. Influence of interferents for sulfonamide (SA)

\begin{tabular}{ccccc}
\hline Analyte & Interferent & $\begin{array}{c}\text { Peak } \\
\text { current } / \mu \mathrm{A}\end{array}$ & $\begin{array}{c}\text { Change } \\
\text { rate /\% }\end{array}$ & $\begin{array}{c}\text { Relative } \\
\text { error / \% }\end{array}$ \\
\hline none & 7.890 & 0 & 0 \\
& glucose & 7.497 & 5.24 & 4.98 \\
sucrose & 7.793 & 1.24 & 1.23 \\
$\mathrm{SA}$ & ascorbic acid & 7.683 & 2.69 & 2.62 \\
& $\mathrm{KCl}$ & 7.668 & 2.90 & 2.81 \\
& $\mathrm{NaCl}$ & 7.845 & 0.57 & 0.57 \\
& $\mathrm{CaCl}$ & 7.852 & 0.48 & 0.48 \\
& $\mathrm{NH}_{4} \mathrm{Cl}$ & 7.796 & 1.20 & 1.19 \\
& $\mathrm{MgSO}_{4}$ & 7.685 & 2.67 & 2.60 \\
\hline
\end{tabular}

\section{Determination of sulfonamides}

The steady-state current response of the optimized sensor system to SAs was examined. Figure 9 shows the currenttime response of the DMF/carboxyl/MWCNTs/GCE in a continuously mildly magnetic stirred solution containing BR under the optimized experimental 
Table 2. Influence of interferents for sulfadiazine (SDZ)

\begin{tabular}{|c|c|c|c|c|}
\hline Analyte & Interferent & $\begin{array}{c}\text { Peak } \\
\text { current } / \mu \mathrm{A}\end{array}$ & $\begin{array}{l}\text { Change } \\
\text { rate / \% }\end{array}$ & $\begin{array}{l}\text { Relative } \\
\text { error / \% }\end{array}$ \\
\hline \multirow{9}{*}{ SDZ } & none & 6.735 & 0 & 0 \\
\hline & glucose & 6.487 & 3.82 & 3.69 \\
\hline & sucrose & 6.695 & 0.60 & 0.60 \\
\hline & ascorbic acid & 6.539 & 3.00 & 2.91 \\
\hline & $\mathrm{KCl}$ & 6.547 & 2.87 & 2.80 \\
\hline & $\mathrm{NaCl}$ & 6.706 & 0.43 & 0.43 \\
\hline & $\mathrm{CaCl}_{2}$ & 6.683 & 0.78 & 0.77 \\
\hline & $\mathrm{NH}_{4} \mathrm{Cl}$ & 6.569 & 2.53 & 2.46 \\
\hline & $\mathrm{MgSO}_{4}$ & 6.493 & 3.72 & 3.60 \\
\hline
\end{tabular}

Table 3. Influence of interferents for sulfamethoxazole (SMZ)

\begin{tabular}{|c|c|c|c|c|}
\hline Analyte & Interferent & $\begin{array}{c}\text { Peak } \\
\text { current } / \mu \mathrm{A}\end{array}$ & $\begin{array}{l}\text { Change } \\
\text { rate } / \%\end{array}$ & $\begin{array}{l}\text { Relative } \\
\text { error / \% }\end{array}$ \\
\hline & none & 7.561 & 0 & 0 \\
\hline & glucose & 7.183 & 5.26 & 5.00 \\
\hline & sucrose & 7.356 & 2.79 & 2.71 \\
\hline & ascorbic acid & 7.261 & 4.13 & 3.97 \\
\hline \multirow[t]{5}{*}{ SMZ } & $\mathrm{KCl}$ & 7.350 & 2.87 & 2.80 \\
\hline & $\mathrm{NaCl}$ & 7.239 & 4.45 & 4.26 \\
\hline & $\mathrm{CaCl}_{2}$ & 7.407 & 2.08 & 2.04 \\
\hline & $\mathrm{NH}_{4} \mathrm{Cl}$ & 7.432 & 1.74 & 1.71 \\
\hline & $\mathrm{MgSO}_{4}$ & 7.219 & 4.74 & 4.52 \\
\hline
\end{tabular}

Table 4. Influence of interferents for sulfamethazine (SM2)

\begin{tabular}{ccccc}
\hline Analyte & Interferent & $\begin{array}{c}\text { Peak } \\
\text { current / } \mu \mathrm{A}\end{array}$ & $\begin{array}{c}\text { Change } \\
\text { rate / \% }\end{array}$ & $\begin{array}{c}\text { Relative } \\
\text { error / \% }\end{array}$ \\
\hline none & 8.381 & 0 & 0 \\
glucose & 7.975 & 5.09 & 4.84 \\
sucrose & 8.103 & 3.43 & 3.32 \\
ascorbic acid & 8.025 & 4.44 & 4.25 \\
& $\mathrm{KCl}$ & 8.250 & 1.59 & 1.56 \\
$\mathrm{NaCl}^{2}$ & 8.008 & 4.66 & 4.45 \\
$\mathrm{CaCl}_{2}$ & 8.237 & 1.75 & 1.72 \\
$\mathrm{NH}_{4} \mathrm{Cl}$ & 7.986 & 4.97 & 4.71 \\
$\mathrm{MgSO}_{4}$ & 7.990 & 4.90 & 4.67 \\
\hline
\end{tabular}

conditions. A fast, sensitive response was achieved to the successive addition of SA. The modified electrode exhibited a linear calibration in the concentration range of SA from $5.0 \times 10^{-7}$ to $1.1 \times 10^{-4} \mathrm{~mol} \mathrm{~L}^{-1}$, with a slope of $50.1 \mathrm{nA} \mathrm{\mu M}^{-1}$ and a correlation coefficient $\left(\mathrm{R}^{2}\right)$ of $0.999(\mathrm{n}=15)$.
The limit of detection (LOD) was $1.65 \times 10^{-8} \mathrm{~mol} \mathrm{~L}^{-1}$ (signal to noise ratio $=3$ ). These results show that the DMF/carboxyl/MWCNTs/GCE was useful for the simple and rapid determination of $\mathrm{SA}$ in real samples. The current-time responses of SM2, SDZ and SMZ were also investigated on the modified elctrode. In the range of $5.0 \times 10^{-7}$ to $0.95 \times 10^{-5} \mathrm{~mol} \mathrm{~L}^{-1}$, the regressive equations of SDZ and SMZ were $\mathrm{i}_{\mathrm{pa}}(\mu \mathrm{A})=0.623 \mathrm{c}+0.475\left(\mathrm{R}^{2}=0.997\right)$, $i_{\text {pa }}(\mu A)=0.890 c+0.488\left(R^{2}=0.996\right)$, in the range of $5.0 \times 10^{-7}$ to $10.95 \times 10^{-5} \mathrm{~mol} \mathrm{~L}^{-1}$; the regressive equations of SM2 was $\mathrm{i}_{\mathrm{pa}}(\mu \mathrm{A})=0.472 \mathrm{c}+0.215\left(\mathrm{R}^{2}=0.990\right)$; and the LODs of SDZ, SMZ and SM2 were $6.76 \times 10^{-8}, 9.41 \times 10^{-8}$ and $3.19 \times 10^{-8} \mathrm{~mol} \mathrm{~L}^{-1}$, respectively.

\section{Analysis of real samples}

The resulted DMF/carboxyl/MWCNTs/GCE was evaluated by performing reccovery tests for SA, SM2, SDZ and SMZ in pork samples, respectively. Firstly, $0.5 \mathrm{~g}$ of mashed pork samples were sonicated by using $1 \mathrm{~mL}$ ethyl acetate for $10 \mathrm{~min}$, and then centrifuged at 5,000 rpm for $10 \mathrm{~min}$. The supernatant was collected and added in $20 \mathrm{~mL}$ BR solution. Thereafter, the resultant BR containing different concentration of SA was transferred to a cell for the recovery determination. The analyses of real samples for SM2, SDZ and SMZ were tested in the same way and the results are shown in Table 5. The recoveries for SAs standards added were 85.43 to $102.25 \%$. Furthermore, the electrochemical behavior of the DMF/carboxyl/MWCNTs/GCE was compared to the other previous electrodes used for the SAs detection as shown in Table 6. The results demonstrated that the modified GCE showed good performance in terms of LOD and linear range, which meant that the DMF/carboxyl/ MWCNTs/GCE was promising for analytical applications; therefore, the sensor system we had developed might provide a useful tool for determining SAs in real samples.

\section{Repeatability and stability of DMF/carboxyl/MWCNTs/GCE}

The repeatability of the modified electrode was investigated by detecting $1.0 \times 10^{-4} \mathrm{~mol} \mathrm{~L}^{-1} \mathrm{SAs}$. As a result, a low relative standard deviation (RSD) of $0.62 \%$ was observed for eight successive assays. After eight successive assays, the response signal of the sensor still remained up to $99.1 \%$ of its initial value. The stability of the sensor was investigated by measuring its response current to $1.0 \times 10^{-4} \mathrm{~mol} \mathrm{~L}^{-1} \mathrm{SAs}$ over 7 days. When not used, the sensor was stored at $4{ }^{\circ} \mathrm{C}$. After 7 days, the current response of the sensor remained up to $95.58 \%$ of its initial value, which indicated the reliability of the fabrication procedure. 

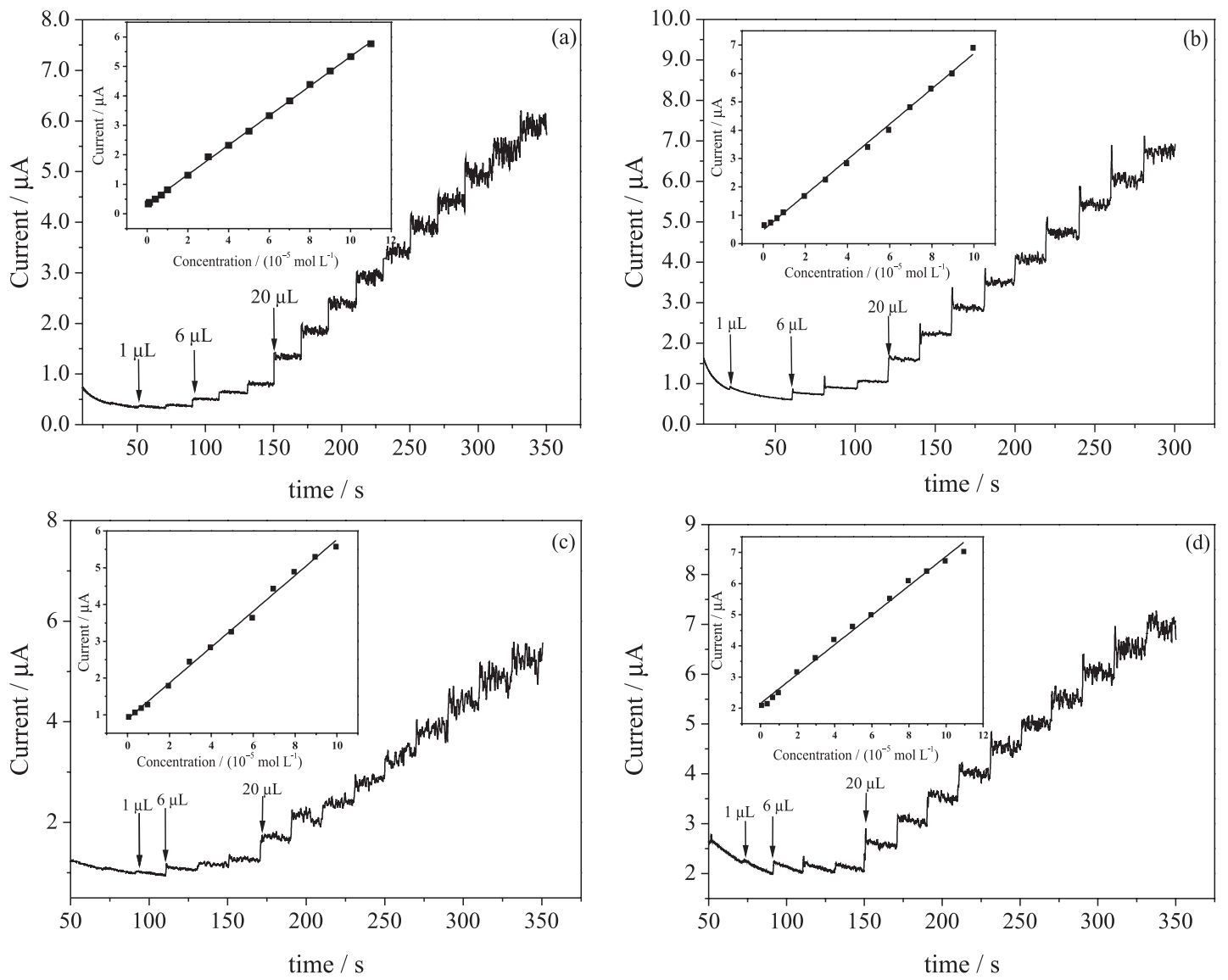

Figure 9. Amperometric current-time curve response for successive addition of (a) sulfonamide (SA); (b) sulfadiazine (SDZ); (c) sulfamethoxazole (SMZ); and (d) sulfamethazine (SM2). Insets show the plot of current change vs. SA, SDZ, SMZ and SM2 concentration.

Table 5. Recovery tests of sulfonamide (SA), sulfamethazine (SM2), sulfadiazine (SDZ) and sulfamethoxazole (SMZ) in pork samples

\begin{tabular}{lcccc}
\hline Analyte & $\begin{array}{c}\text { Added level / } \\
\left(10^{-5} \mathrm{~mol} \mathrm{~L}^{-1}\right)\end{array}$ & $\begin{array}{c}\text { Found / } \\
\left(10^{-5} \mathrm{~mol} \mathrm{~L}^{-1}\right)\end{array}$ & $\begin{array}{c}\text { Mean of } \\
\text { recovery / } \%\end{array}$ & $\begin{array}{c}\mathrm{RSD}^{\mathrm{a}} / \\
\%\end{array}$ \\
\hline \multirow{3}{*}{ SA } & 1 & 0.96 & 95.81 & 3.18 \\
& 3 & 2.74 & 91.25 & 3.99 \\
& 5 & 5.12 & 102.38 & 2.17 \\
& 7 & 6.89 & 98.34 & 4.2 \\
\hline \multirow{3}{*}{ SM2 } & 1 & 0.97 & 96.78 & 1.53 \\
& 3 & 3.02 & 100.56 & 2.15 \\
& 5 & 4.88 & 97.67 & 2.71 \\
& 7 & 6.62 & 94.55 & 1.43 \\
\hline \multirow{3}{*}{ SDZ } & 1 & 0.9 & 89.65 & 3.86 \\
& 3 & 2.85 & 94.86 & 2.71 \\
& 5 & 4.27 & 85.43 & 3.35 \\
& 7 & 6.97 & 99.56 & 1.15 \\
\hline \multirow{3}{*}{ SMZ } & 1 & 0.88 & 87.65 & 2.05 \\
& 3 & 2.7 & 90.14 & 3.72 \\
& 5 & 4.5 & 89.96 & 4.29 \\
& 7 & 7.16 & 102.25 & 2.79 \\
\hline
\end{tabular}

${ }^{\mathrm{a}} \mathrm{n}=3$. RSD: Relative standard deviation.

\section{Conclusions}

In this work, it was successfully immobilized on GCE surface by using carboxyl MWCNTs in DMF media to form DMF/carboxyl/MWCNTs/GCE. The resulting sensor performed high electrochemical conductivity, fast electron transfer, and presented sensitive and selective response to SAs in real samples with low LOD, good repeatability and stability. In addition, due to its convenience of the preparation and process, a fast, accurate way of detection for SAs could be achieved, and it would be convenient for operation by unskilled users.

\section{Acknowledgments}

This work was supported by National Natural Science Foundation of China (Grant No. 61301037), Foundation of Henan Educational Committee (Grant No. 13A550194), Key Project of Zhengzhou (Grant No. 20120663), Plan for Scientific Innovation Talent of Henan University of Technology (Grant No. 2012CXRC02), Fundamental Research Funds for the Henan Provincial Colleges and Universities (Grant No. 2014YWQQ05), Youth Backbone 
Table 6. Reports using other modified electrode and $N, N$-dimethylfomamide (DMF)/carboxyl/multiwalled carbon nanotubes (MWCNTs)/glassy carbon electrode (GCE) for electrochemical detection of sulfonamides (SAs)

\begin{tabular}{|c|c|c|c|c|c|c|}
\hline Modified electrode & $\begin{array}{l}\text { Detection } \\
\text { method }\end{array}$ & $\begin{array}{l}\text { Linearity range / } \\
(\mu \mathrm{mol} \mathrm{L}-1)\end{array}$ & $\begin{array}{c}\text { LOD / } \\
\left.(\mu \mathrm{mol} \mathrm{L})^{-1}\right)\end{array}$ & Analyte & Real sample & Reference \\
\hline \multirow[t]{2}{*}{ BDD electrode } & SWV & $8.01-119$ & 2.19 & SDZ & pharmaceutical & Cristine et al. ${ }^{44}$ \\
\hline & SWV & $6.10-60.1$ & 1.15 & SMZ & pharmaceutical & Cristine et al. ${ }^{44}$ \\
\hline MWCNTCOOH/BA-SPCE & DPV & $1.00-70.0$ & 0.30 & sulfasalazine & $\begin{array}{l}\text { tablet, urine and } \\
\text { human serum }\end{array}$ & Susan et $a l . .^{45}$ \\
\hline Poly/MWCNTs-Nafion GCE & amperometry & $0.50-43.5$ & 0.17 & SDZ & human urine & Hong et al. ${ }^{40}$ \\
\hline $\mathrm{SbFE}$ & SWV & $3.00-250$ & 0.78 & sulfasalazine & tablet & Biljana et al. ${ }^{46}$ \\
\hline BiFE & SWV & $5.00-350$ & 1.40 & sulfasalazine & tablet & Biljana et al. ${ }^{47}$ \\
\hline Carboxyl-MWCNTs/GCE & amperometry & $0.50-110$ & $0.02-0.09$ & $\begin{array}{c}\text { SA, SDZ, SMZ and } \\
\text { SM2 }\end{array}$ & pork & this work \\
\hline
\end{tabular}

BA-SPCE: Home-made screen-printed carbon electrode; BDD: boron-doped diamond; BiFE, bismuth film electrode; DPV: differential pulse voltammetry; MWCNTCOOH: carboxylic acid-functionalized multiwalled carbon nanotube; Poly: cobalt tetraaminophthalocyanine [poly $\left(\mathrm{Co}{ }^{\mathrm{II}} \mathrm{TAPc}\right)$ ]; $\mathrm{SbFE}$ : antimony film electrode; SDZ: sulfadiazine; SMZ: sulfamethoxazole; SM2: sulfamethazine; SWV: square wave voltammetry.

Teacher Training Program of Henan University of Technology, and Master's Degree Thesis Cultivation Project of Henan University of Technology (Grant No. PY201504).

\section{References}

1. Gentili, A.; Perret, D.; Marchese, S.; Sergi, M.; Olmi, C.; Curini, R.; J. Agric. Food Chem. 2004, 52, 4614.

2. Hruska, K.; Franek, M.; Vet. Med.(Prague, Czech Repub.) 2012, $57,2$.

3. Haasnoot, W.; Bienenmann-Ploum, M.; Lamminmaki, U.; Swanenburg, M.; Rhijn, H.; Anal. Chim. Acta 2005, 552,87 .

4. Borràs, S.; Companyó, R.; Guiteras, J.; J. Agric. Food Chem. 2011, 59, 5240 .

5. Shao, B.; Dan, D.; Wu, Y. N.; Hu, J. Y.; Meng, J.; Tu, X. M.; Xu, S. K.; Anal. Chim. Acta 2005, 546, 174.

6. Andrade, L. S.; Moraes, M. C.; Rocha-Filho, R. C.; FatibelloFilho, O.; Cass, Q. B.; Anal. Chim. Acta 2009, 654, 127.

7. Xu, Y.; Ding, J.; Chen, H. Y.; Zhao, Q.; Hou, J.; Yan, J.; Wang, H.; Ding, L.; Ren, N. Q.; Food Chem. 2013, 140, 83.

8. García-Galán, M. J.; Díaz-Cruz, M. S.; Barceló, D.; Talanta 2010, $81,355$.

9. Chung, H. H.; Lee, J. B.; Chung, Y. H.; Lee, K. G.; Food Chem. 2009, 113, 297.

10. Mendoza, J. H.; Maggi, L.; Bonetto, L.; Carmena, B. R.; Lezana, A.; Mocholí, F. A.; Food Chem. 2012, 134, 1149.

11. de la Cruz, M. N. S.; Soares, R. F.; Marques, A. S. F.; de AquinoNeto, F. R.; J. Braz. Chem. Soc. 2011, 22, 454.

12. Salami, F. H.; Queiroz, M. E. C.; J. Braz. Chem. Soc. 2011, 22, 1656.

13. Lara, J.; García-Campaña, A. M.; Neusüss, C.; Alés-Barrero, F.; J. Chromatogr. A 2009, 1216, 3372.

14. Fuh, M. R. S.; Chu, S.Y.; Anal. Chim. Acta 2003, 499, 215.
15. Font, G.; Juan-García, A.; Picó, Y.; J. Chromatogr. A 2007, 1159, 233.

16. Wen, Y.Y.; Li, J. H.; Zhang, W. W.; Chen, L. X.; Electrophoresis 2011, 32, 2131.

17. Reeves, V. B.; J. Chromatogr. B: Biomed. Sci. Appl. 1999, 723, 127.

18. Chiavarino, B.; Crestoni, M. E.; Marzio, A. D.; Fornarini, S.; J. Chromatogr. B: Biomed. Sci. Appl. 1998, 706, 269.

19. Naziha, A.; Amel, T.; Jean, P. C.; J. Chromatogr. A 2005, 1071, 71.

20. Injac, R.; Kocevar, N.; Kreft, S.; Anal. Chim. Acta 2007, 594, 119.

21. Kowalski, P.; Plenis, A.; Olędzka, I.; Konieczna, L.; J. Pharm. Biomed. Anal. 2011, 54, 160.

22. Lamba, S.; Sanghi, S. K.; Asthana, A.; Shelke, M.; Anal. Chim. Acta 2005, 552, 110.

23. Nurullah, Ş.; Senem, Ş.; Güleren, Ö.; Adil, D.; J. Braz. Chem. Soc. 2010, 21, 1952.

24. Won, S. Y.; Lee, C. H.; Chang, H. S.; Kim, S. O.; Lee, S. H.; Kim, D. S.; Food Control 2011, 22, 1101.

25. Lu, K. H.; Chen, C. Y.; Lee, M. R.; Talanta 2007, 72, 1082.

26. Yu, C. H.; Hu, B.; Talanta 2012, 90, 77.

27. Iijima, S.; Nature (London, U. K.) 1991, 354, 57.

28. Baughman, R. H.; Zakhidov, A. A.; Heer, W. A.; Science (Washington, DC, U. S) 2002, 297, 788.

29. Shahrokhian, S.; Asadian, E.; Electrochim. Acta 2010, 55, 667.

30. Gheibi, S.; Karimi-Maleh, H.; Khalilzadeh, M. A.; Bagheri. H.; J. Food Sci. Technol. (New Delhi, India) 2015, 52, 276.

31. Sadeghi, S.; Garmroodi, A.; J. Electroanal. Chem. 2014, 727, 172.

32. Łuczak, T.; Electrochim. Acta 2009, 54, 5864.

33. Liu, Y. J.; Yin, F.; Long, Y. M.; Zhang, Z. H.; Yao, S. Z.; J. Colloid Interface Sci. 2003, 258, 77.

34. Khan, R.; Dhayal, M.; Biosens. Bioelectron. 2009, 24, 1703. 
35. Zuo, X.; Zhang, H.; Li, N.; Sens. Actuators, B 2012, 161, 1077.

36. Sadeghi, S.; Garmroodi, A.; J. Electroanal. Chem. 2014, 727, 173.

37. Cai, M. Z.; Zhu, L.; Ding, Y. P.; Wang, J. X.; Li, J. S.; Du. X. Y.; Mater. Sci Eng., C 2012, 32, 2625.

38. Wei, Y. L.; Ji, X. B.; Dang, X. P.; Hu, S.S.; Bioelectrochemistry 2003, 61, 53.

39. Thammasoontaree, N.; Rattanarat, P.; Ruecha, N.; Siangproh, W.; Rodthongkum, N.; Chailapaku, O.; Talanta 2014, 123, 117.

40. Hong, X. P.; Zhu, Y.; Zhang, Y. Z.; J. Zhejiang Univ., Sci., B 2012, 13, 505.

41. Sadeghi, S.; Motaharian, A.; Moghaddam, A. Z.; Sens. Actuators, B 2012, 168, 341.
42. Zhou, Q.; Yang, L.; Wang, G. C.; Yang, Y.; Biosens. Bioelectron. 2013, 49, 30.

43. Wang, Y.; Bi, C. Y.; J. Mol. Liq. 2013, 177, 30.

44. Cristine, D.; Otoniel, C.; Braga, C.; Almir, S.; Sens. Actuators, B 2008, 135, 66.

45. Susan, S.; Aziz, G.; J. Electroanal. Chem. 2014, 727, 171.

46. Biljana, N.; Samo, H.; Electrochim. Acta 2011, 58, 523.

47. Biljana, N.; Branimir, S.; Samo, H.; Electrochim. Acta 2009, 54,5678 .

Submitted: January 31, 2016

Published online: April 15, 2016 